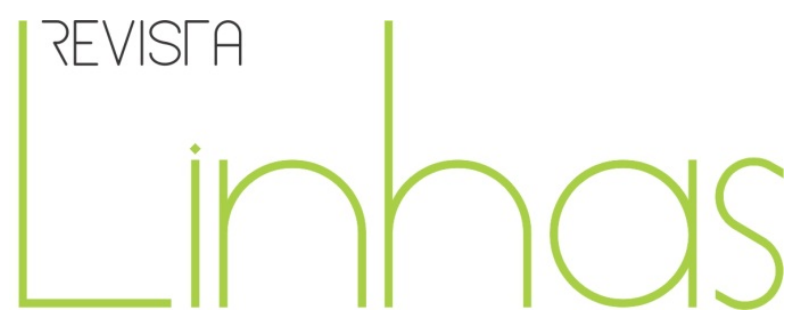

\title{
As tecnologias digitais na formação inicial do pedagogo
}

\section{Resumo}

Este artigo tem como objetivo geral analisar as percepções que os discentes do Curso de Pedagogia têm sobre as tecnologias digitais no seu processo de formação, verificando se a formação vivenciada por eles na graduação agregou contribuições para uso em sua futura atuação docente e, se as experiências vivenciadas no curso, em relação ao uso das tecnologias, favoreceram para lhes dar a necessária segurança em relação à utilização das novas tecnologias digitais no contexto pedagógico. Para o desenvolvimento deste estudo, utilizaram-se como metodologia de pesquisa pressupostos da abordagem qualitativa, constituindo-se em um estudo exploratório-explicativo. A revisão bibliográfica e um questionário compõem o conjunto de procedimentos investigativos. O cenário da pesquisa foi representado por uma universidade pública do interior do estado do Paraná e, como público, foram eleitos os discentes do último ano de um Curso de Pedagogia. Os resultados elucidam que os discentes finalizam seu curso com um arcabouço muito restrito no que se refere aos aspectos pedagógicos e técnicos para o uso das tecnologias digitais na educação e, ainda revelam que somente uma disciplina trata da temática durante o curso, fator que limita as experiências voltadas à docência e acarreta insegurança. Outro aspecto relevante se refere à limitada formação dos docentes formadores e a maneira como usam as tecnologias digitais em suas aulas.

Palavras-chave: Professores; Formação tecnológica educacional; Ensino; Aprendizagem.

\section{Dirce Aparecida Foletto de Moraes}

Doutoranda em Educação pela

Faculdade de ciências e

Tecnologias da Universidade

Estadual Paulista -

UNESP/Presidente Prudente Brasil

dircemoraes2007@gmail.com

\section{Joyce Gomes}

Mestre em Educação pela

Faculdade de Ciências e

Tecnologias da Universidade

Estadual Paulista -

UNESP/Presidente Prudente Brasil

joyceg1@gmail.com

\section{Sergio Gouveia}

Mestrando em Educação pela

Faculdade de Ciências e

Tecnologias da Universidade

Estadual Paulista -

UNESP/Presidente Prudente Brasil

sagouveiajr@gmail.com

\section{Para citar este artigo:}

MORAES, Dirce Aparecida Foletto de; GOMES, Joyce; GOUVEIA, Sergio. As tecnologias digitais na formação inicial do pedagogo. Revista Linhas. Florianópolis, v. 16, n. 30, p. 214 - 234, jan./abr. 2015. 


\title{
The digital technologies in the pedagogue initial education
}

\begin{abstract}
This article aims to analyze the perceptions of Pegadogy's students about the digital technologies in their formation process, to verify if these formation's experienced by them at graduation aggregate contributions to the use of these technologies in their future teaching practice and to estimate if their experiences during the course have contributed to give them the necessary security about the new digital technologies in the teaching context. To the development of this study, it was used a qualitative research methodology, consisting in an exploratoryexplanatory study. A literature review and a questionnaire comprising the set of investigative procedures. The research scene was represented by a public university students in the state of Parana, Brazil, attending the last year of Pedagogy. The results elucidate that the students finalize the Pedagogy course with a very restricted framework with regard to pedagogic and technical aspects for the use of digital technologies in education and further reveal that only one discipline deals with the themes during the course, a factor that limits their experiences and brings insecurity. Another relevant aspect refers to the limited teachers formation which should form and the way they use digital technologies in their classes.
\end{abstract}

Keywords: Teachers; Educational technology training; teaching; learning. 


\section{Introdução}

As tecnologias digitais vêm exercendo um importante papel na sociedade, porque “[...] representam uma força determinante do processo de mudança social, surgindo como a trave-mestra de um novo tipo de sociedade, a sociedade da informação. [...]" (PONTE, 2000, p. 64). Ante esta evidência, pode-se afirmar que seu maior potencial está na capacidade de democratizar o acesso e a condição de aprendizagem em qualquer lugar e em qualquer contexto. Neste sentido, significa que as tecnologias digitais colaboram para que "[...] mais pessoas tenham acesso à formação e à educação [...]" (COLL, MAURI E ONRUBIA, 2010, p. 68).

Tais fatores são essenciais quando o objetivo maior é favorecer a construção do conhecimento e o desenvolvimento de condições para que o sujeito participe da chamada sociedade da informação. No entanto, a preocupação de pesquisadores e teóricos que defendem o seu uso na educação vai além da possibilidade do acesso e da democratização da informação. A literatura especializada tem demonstrado a possibilidade de as tecnologias digitais contribuírem para que professores e alunos assumam uma parceria no processo de construção do conhecimento, trabalhando de forma colaborativa e encontrando novas formas de ensinar e de aprender.

Porém a realidade se apresenta de outra forma. Estudos realizados por diferentes pesquisadores (ALAVA, 2002; SILVA, 2002; VALENTE, 2002; BARRETO, 2004; SANCHO; HERNANDEZ, 2006; FREITAS, 2009; COLL; MONEREO, 2010) revelam que o uso destas ferramentas nas escolas se volta, normalmente, para uma perspectiva instrumental, que acaba resultando em práticas pedagógicas mecânicas e reprodutoras e não em ações que possibilitem experiências pedagógicas inovadoras e significativas, capazes de contribuir para modificar o ensino e a aprendizagem. Isso ocorre "[...] justamente porque as novas tecnologias da informação e comunicação que abrem novas possibilidades implicam novos desafios para o trabalho docente. E o enfrentamento desse desafio requer, como núcleo, a reflexão sobre práticas pedagógicas" (BARRETO, 2002, p. 110) e não apenas a inserção do instrumental tecnológico na escola ou na aula.

Esta mudança não exige somente uma “[...] outra postura do profissional da educação perante o conhecimento desenvolvido com seus alunos, representa profunda 
ruptura com as formas anteriores de ensino/aprendizagem" (FREITAS, 2009, p. 20), mas necessita de uma formação adequada que deve começar bem antes de o educador adentrar o espaço escolar.

É no contexto da formação inicial que o futuro docente precisa vivenciar experiências capazes de lhe dar condições e espaços para refletir sobre o uso pedagógico das tecnologias digitais e compreender que, nesta prática, seu papel se modifica, já que “[...] deixa de ser o contador de história que imobiliza o conhecimento" (SILVA, 2012, p. 91) para tornar-se um agente de transformação que oferece diferentes possibilidades de aprendizagens. Ele precisa entender que a "[...] aprendizagem é interativa porque ocorre mediante a participação, bidirecionalidade e multiplicidade de conexões [...]" (SILVA, 2012, p. 92) proporcionadas pelas tecnologias digitais.

No entanto, nos cursos de formação inicial de professores, o currículo normalmente prioriza a preparação quanto ao fazer docente e em relação ao cotidiano legal da escola e - quando muito - oferece espaços restritos à preparação para o trabalho com as tecnologias. Sobre esta questão, Marinho e Lobato (2008) expressam que "[...] eles não são preparados para usá-lo na futura ação profissional no magistério". Em alguns cursos, como é o caso de Pedagogia, as tecnologias são contempladas como disciplina, no entanto, em outros, nem como conteúdo. Esta situação é preocupante, uma vez que, segundo Valente (1999), a formação do docente é o componente essencial para que as práticas pedagógicas auxiliadas pelos artefatos tecnológicos ocorram da forma esperada.

No que se refere especificamente ao Curso de Pedagogia, a Resolução CNE/CP $n^{\circ}$ 1/2006, de 15 de maio de 2006, instituiu as Diretrizes Curriculares Nacionais para o referido curso e estabelece, no artigo $5^{\circ}$, inciso VII, que o egresso deve estar apto a "[...] relacionar as linguagens dos meios de comunicação à educação, nos processos didáticopedagógicos, demonstrando domínio das tecnologias de informação e comunicação adequadas ao desenvolvimento de aprendizagens significativas" (BRASIL, 2006, p. 2).

O exposto pelas Diretrizes confirma a necessidade de uma formação que dê ao licenciado condições de entender os significados das tecnologias digitais no seu fazer docente. A falta de uma formação adequada que ajude o futuro educador a desmistificar concepções cristalizadas reforça, com frequência, práticas equivocadas e de senso comum no exercício da docência. Diante desta problemática, propusemo-nos a refletir 
sobre percepções que os alunos do último ano do Curso de Pedagogia de uma instituição pública do interior do Paraná têm a respeito de sua formação para o uso das tecnologias em sua futura ação docente.

\section{As tecnologias digitais no contexto da formação inicial}

As tecnologias estão presentes em muitos espaços da sociedade e se inseriram rapidamente no cenário educacional. Além disso, têm sido avaliadas como alternativas viáveis para favorecer experiências positivas e inovadoras no processo de ensino e aprendizagem, apresentando-se como um “potencial transformador”.

Entre os que defendem o uso delas na escola, há a justificativa da superação de uma pedagogia tradicional e da melhoria na qualidade do ensino, por serem entendidas como "instrumentos poderosos para promover a aprendizagem" (COLL; MAURI; ONRUBIA, 2010, p. 68); como catalizadores para a democratização do conhecimento; como facilitadores do acesso à informação, à participação política e à emancipação na chamada Sociedade da Informação.

Para que sua utilização ocorra de maneira eficaz e ajude a diminuir não só a exclusão social como as desigualdades sociais, sem repetir as velhas formas de dominação e falta de diálogo na realidade escolar opressora (FREIRE, 1975; 1976), é preciso que haja compromisso com a ética do compartilhamento, que Pretto (2010) chama de ética hacker. Com o advento da Web 2.0 ${ }^{1}$, que consiste, fundamentalmente, na superação das comunicações do tipo broadcasting ${ }^{2}$ e cultivo de formas de interações e colaborações humanas, essas ferramentas pressupõem que sejam tomadas como novas formas de ensinar e aprender e têm como princípio a ideia da aprendizagem colaborativa, cuja prática se distancia daquelas encontradas em "[...] uma escola distribuidora de informações, verticalizadas e produzidas de forma centralizada, em que aos estudantes só resta a opção de consumir" (PRETTO, 2010, p. 315).

\footnotetext{
${ }^{1}$ Web 2.0 é a segunda geração de serviços online e refere-se a um determinado período tecnológico, a um conjunto de novas estratégias mercadológicas e a processos de comunicação mediados pelo computador, iniciando uma estrutura integrada de funcionalidades e conteúdo (PRIMO, 2007, p. 1-2).

${ }^{2}$ Broadcasting: a perspectiva de comunicação em que tudo é produzido e distribuído de forma centralizada, beneficiando-se da estrutura tecnológica disponível (PRETTO, 2008, p. 77).
} 
Entretanto, apesar de muitas promessas de revolução na educação e dos benefícios que as tecnologias podem trazer, é preciso entendê-las como possibilidades e não como garantia, ou seja, como meio e não como fim. Somente a inserção dos meios tecnológicos não garante modificações e avanços na educação, é comum serem vistos como "modismos" ou como mais uma das encenações da Sociedade do Espetáculo, em que, de acordo com Debord (2003), são importantes as coisas que aparecem e não exatamente o seu propósito.

As tecnologias digitais seriam, sob esta perspectiva, mais um dos elementos educacionais inovadores, que - por haver falta de orientação, acompanhamento e formação daqueles que vão atuar diretamente com tais instrumentos e, consequentemente, os resultados de seus usos não corresponderem às expectativas e aos objetivos propostos - acabam em desuso ou tendo um uso inadequado. Alguns professores, por não terem condições de refletir sobre sua prática ou, ainda, por não disporem de tempo nem de recursos, acabam convertendo-se em profissionais que agem de acordo com o que lhes pede o mercado, e não de acordo com o que exige a ciência (SACRISTÁN, 2002, p. 82) e, ainda que se sintam frustrados com suas experiências tecnológicas, sentem-se pressionados a usarem instrumentos das tecnologias digitais e até persistem em suas tentativas - apesar de representarem novas maneiras de fazer o velho.

Enquanto potencial transformador, as tecnologias digitais podem ser entendidas como ferramentas que "[...] estimulan la experimentación, reflexión y la generación de conocimientos individuales y colectivos, favoreciendo la conformación de un ciberespacio de intercreatividad que contribuye a crear un entorno de aprendizaje colaborativo" (ROMANI E KUKLINKI, 2007, p. 101) em diferentes tempos e espaços. Orientada por este pressuposto, a aprendizagem pode superar o caráter individual e passar a ser cooperativa e colaborativa, oportunizando ao sujeito aprendente ser também o protagonista do processo. 
em

Em relação a esta questão, Silva (2002, p. 81) explica que o grande desafio consiste

[...] compreender que a chegada dessas tecnologias permite passar de um modelo que privilegia a lógica da instrução, da transmissão e assimilação da informação para um modelo pedagógico cujo funcionamento se baseia na construção colaborativa de saberes, na abertura aos contextos sociais e culturais, à diversidade dos alunos, aos conhecimentos, experimentações e interesses [...].

No entanto, os resultados da pesquisa realizada por Gatti e Barreto (2009), sobre os currículos do Curso de Pedagogia no Brasil demonstram que este objetivo não é contemplado, visto que menos de $1 \%$ das disciplinas obrigatórias aborda conhecimentos sobre as tecnologias. No caso das disciplinas optativas, o percentual sobe para $3,2 \%$, um índice ainda muito baixo.

Em consonância com o proposto, o Parecer CNE/CP 9/2001, que instituiu as Diretrizes Curriculares Nacionais para Formação do Professor da Educação Básica, expressa a necessidade de os cursos de licenciatura oferecerem "[...] condições para que os futuros professores aprendam a usar tecnologias de informação e comunicação, cujo domínio é importante para a docência [...]” (BRASIL, 2001, p. 45). Para que estas condições ocorram de fato, é preciso que o discente tenha contato com a temática e com as ferramentas tecnológicas nas diferentes disciplinas do currículo, é preciso também que não limite esta tarefa a uma apenas. É evidente que, se os cursos tiverem como

[...] estratégia levar o computador a todas [ou praticamente todas] disciplinas das licenciaturas, fazendo com que esse recurso permeasse a formação inicial do professor, possivelmente teria maior eficácia já que possibilitaria o desenvolvimento de uma competência para o uso educacional das tecnologias digitais através de sua efetiva incorporação nas várias instâncias e momentos da formação do educador. (MARINHO, 2008, p. 35)

A presente defesa significa que, juntamente com uma disciplina específica que ofereça as bases em relação aos aspectos teóricos e práticos, é imprescindível vivenciar outras experiências relacionadas às tecnologias digitais na formação do licenciado a fim 
de que este possa construir uma bagagem mais ampla sobre as perspectivas em relação ao uso e entendimento destas como ferramentas pedagógicas na educação.

Em suma, mesmo com o entendimento claro de que a graduação é apenas uma das etapas do processo de formação do sujeito, é fundamental que, no curso, seja contemplada a reflexão sobre a prática, bem como a desnaturalização de concepções arraigadas pelo uso para que se possa reconstruí-las sobre novos alicerces. Portanto, ao se pensar na formação inicial do futuro pedagogo, deve-se levar em consideração a inserção das tecnologias digitais nas atividades de sala de aula. Para tanto, é prioritária:

[...] uma revisão do currículo que leve em conta as práticas socioculturais próprias da SI associadas a essas tecnologias e que inclua os objetivos, competências e conteúdos necessários para participação nessas práticas, mesmo que isso obrigue a renunciar a outros objetivos e conteúdos. (COLL; MONEREO, 2010, p. 90)

Assim, é preciso ter clareza de que a "[...] formação no domínio das tecnologias deve constituir um objetivo que deve estar subjacente a qualquer currículo ou plano de formação inicial, contínua e permanente dos professores [...]" (SILVA, 2002, p. 83).

\section{Percurso metodológico}

O presente artigo tem como objetivo geral identificar as percepções que os discentes do último ano do Curso de Pedagogia têm sobre as tecnologias digitais no currículo do curso, bem como se a formação vivenciada na graduação contribuiu para o uso pedagógico de tais artefatos em sua atuação docente. Para responder ao objetivo geral, os objetivos específicos eleitos foram: identificar o valor atribuído pelos discentes às tecnologias digitais no processo de ensino e aprendizagem; identificar se os discentes sentem-se preparados para usar as tecnologias digitais no contexto pedagógico; identificar e analisar as contribuições do Curso de Pedagogia para o uso das tecnologias digitais em sala de aula.

Em relação aos objetivos aqui propostos, esta pesquisa é caracterizada como exploratório-explicativa, com elementos da análise do discurso. Exploratória porque possibilita uma visão geral de um fenômeno, neste caso, as percepções e a formação dos 
discentes para o uso das tecnologias digitais. Gil (2002, p. 27) esclarece que esta tem como propósito “[...] desenvolver, esclarecer e modificar conceitos e idéias, tendo em vista a formulação de problemas mais precisos ou hipóteses pesquisáveis" para que, posteriormente, viabilizem-se outros estudos mais profundos e sistematizados.

Esta pesquisa também é explicativa por ter “[...] como preocupação central identificar os fatores que determinam ou que contribuem para a ocorrência dos fenômenos ou fatos [...]" (GIL, 2002, p. 42), permitindo conhecer a realidade investigada de maneira mais intensa e, ainda, saber "a razão e o porquê das coisas [...]" (GIL, 2002, p. 42). Além disso, a pesquisa apresenta uma abordagem qualitativa quanto aos meios de investigação, por focalizar o processo e priorizar "[...] a interpretação no lugar da mensuração, a descoberta em lugar da constatação, valoriza a indução e assume que fatos e valores estão intimamente relacionados, tornando-se inaceitável uma postura neutra do pesquisador"' (ANDRÉ, 2004, p. 17).

\section{Resultado e discussões}

O Curso participante da pesquisa oferece uma licenciatura plena em Pedagogia, com um total de 3244 horas, reformulado em 2010 para atender às novas exigências das Diretrizes Curriculares Nacionais. Nele, apenas uma, dentre as quarenta e seis disciplinas ofertadas, está diretamente ligada às tecnologias, com 62 horas, sob o nome de “Educação e Tecnologia” e é obrigatória para os alunos do $1^{\circ}$ ano do curso. Nas demais disciplinas, não há nenhuma menção relacionada ao tema nas ementas propostas.

A coleta de dados ocorreu por meio de questionário on line. A solicitação foi feita para as quatro turmas do último ano no final do ano letivo. Dos 34 alunos que assinaram o termo de consentimento livre e esclarecido, apenas 15 responderam o questionário. A hipótese que se tem para esta abstenção é que a utilização da ferramenta on line pode não ter instigado todos a participarem. Cabe mencionar que foi preservada a identidade dos participantes da pesquisa. Para tanto, utilizaram-se códigos para nomeá-los, sendo que a letra "A" se refere a "aluno". Além disso, os textos dos participantes foram mantidos na forma original. Os discentes que responderam o questionário têm entre 21 e 30 anos, sendo 12 do período da manhã e três do período noturno, destes, três já tinham 
outra formação em nível superior e quatro atuam como docentes de educação infantil, $1^{\circ}$ e $2^{\circ}$ ano do ensino fundamental.

Em relação ao valor atribuído pelos discentes às tecnologias digitais, os resultados da pesquisa revelaram que os estudantes dividem-se entre os que as consideram como muito positiva e os que a avaliam como positiva com algumas restrições.

Quadro 1: Valor atribuído às tecnologias digitais

\begin{tabular}{|c|c|c|}
\hline Categoria & $\%$ & Evidências \\
\hline \multirow{3}{*}{ Muito positiva } & \multirow[t]{3}{*}{$42 \%$} & Ela sempre pode ser aliada em tudo que faça. (A.1) \\
\hline & & $\begin{array}{l}\text { Tenho um bom conhecimento sobre as } \\
\text { tecnologias digitais, o que auxilia para que eu } \\
\text { possa estar utilizando-as. (A. 4) }\end{array}$ \\
\hline & & $\begin{array}{l}\text { A tecnologia, hoje em dia, me auxilia em tudo, } \\
\text { desde em responder a uma pequena dúvida, até a } \\
\text { pesquisa acadêmica, trazendo, assim, novos } \\
\text { conhecimentos. (A.5) }\end{array}$ \\
\hline \multirow{6}{*}{ Positiva com algumas restrições } & \multirow[t]{6}{*}{$58 \%$} & $\begin{array}{l}\text { Pode ser negativa ao ocupar maior tempo do que } \\
\text { necessário. (A.2) }\end{array}$ \\
\hline & & $\begin{array}{l}\text { Se a pessoa não souber utilizá-la o uso não terá } \\
\text { êxito. (A.3) }\end{array}$ \\
\hline & & $\begin{array}{l}\text { Se não soubermos o limite, isso pode tomar muito } \\
\text { do nosso tempo. (A.11) }\end{array}$ \\
\hline & & $\begin{array}{l}\text { É necessário um limite, as tecnologias devem ser } \\
\text { um apoio (A.12) }\end{array}$ \\
\hline & & $\begin{array}{l}\text { [...] existe o risco de o equipamento ou } \\
\text { determinada tecnologia não funcionar, pifar, } \\
\text { falhar. (A.15) }\end{array}$ \\
\hline & & $\begin{array}{l}\text { Restrições porque vai extinguir o uso do giz, do } \\
\text { quadro negro e poucos são os alunos que } \\
\text { atualmente utilizam as bibliotecas para a pesquisa, } \\
\text { recorrendo apenas à internet. (A.7) }\end{array}$ \\
\hline
\end{tabular}

Fonte: Os autores

Para o primeiro grupo, a relação com as tecnologias digitais é muito positiva devido à possibilidade e à facilidade que oferecem como aliadas e auxiliares em suas tarefas docentes. Estes expressam opiniões que relacionam as tecnologias ao seu universo de interesses individuais. Já aqueles que se referem às tecnologias com 
restrições, as razões se relacionam, sobretudo, à preocupação com o tempo de uso e, por isso, é necessário limite. Outro aspecto relevante refere-se à preocupação de algumas tecnologias superarem outras.

Estas respostas dão indicadores de que para estes discentes o uso das tecnologias digitais está carregado de limitações, já que elas são vistas como possível ameaça àquilo que já está consolidado. Eles acreditam que seu uso constante pode provocar insegurança e romper barreiras, representando, de certa forma, um perigo. Tais depoimentos revelam uma relação com um ensino unidirecional, que "[...] põe em cena as 'velhas tecnologias': quadro-de- giz, ou alguma superfície em que seja possível escrever o que deve ser copiado e respondido, caderno, caneta e livros" (BARRETO, 2002, p. 65) como garantia de aprendizagem.

É certo que nenhum instrumento tecnológico por si só, do giz à internet, garante a eficiência do ensino ou resolve os problemas educacionais: o que precisa ser diferente não é o equipamento, mas as ações implantadas, as experiências vivenciadas e o conhecimento construído.

O problema não é o aluno trocar a biblioteca real pela virtual e sim o que se faz nesta biblioteca, se a pesquisa realizada não servir para construir novos conhecimentos, mas apenas para reproduzir informações e entregá-las ao professor para ganhar uma nota, pouca diferença faz o ambiente no qual se estuda. O mesmo vale para o professor, porque "[...] não são os instrumentos que mudam as práticas docentes profundamente enraizadas" (SANCHO; HERNANDEZ, 2006, p. 36) e sim a ressignificação das suas concepções e da sua prática.

A falta de uma infraestrutura adequada - revelada no depoimento de um estudante - evidencia-se como um aspecto ameaçador para o professor e precisa ser considerada nos estudos relacionados ao uso das tecnologias digitais na prática escolar. A quantidade de computadores e outros equipamentos, as condições de uso destes, a conexão com a internet e a falta de pessoas especializadas favorecem o desestímulo do professor, por isto, “[...] enquanto não houver melhoras substanciais nesses aspectos, o impacto das TIC sobre as práticas educacionais docentes e sobre os processos de ensino e aprendizagem continuará sendo, necessariamente, limitado" (COLL; MONEREO, 2010, p. 73). 
Além da falta de infraestrutura, outro fator que precisa ser considerado é a formação adequada que possibilite modificações na maneira de utilizar as ferramentas, para que não sirva, na escola, apenas como extensão do uso que fazem destes dispositivos fora dela. O quadro 2 apresenta as considerações dos estudantes sobre a formação para o uso das tecnologias digitais.

Quadro 2: Formação para o uso das tecnologias digitais

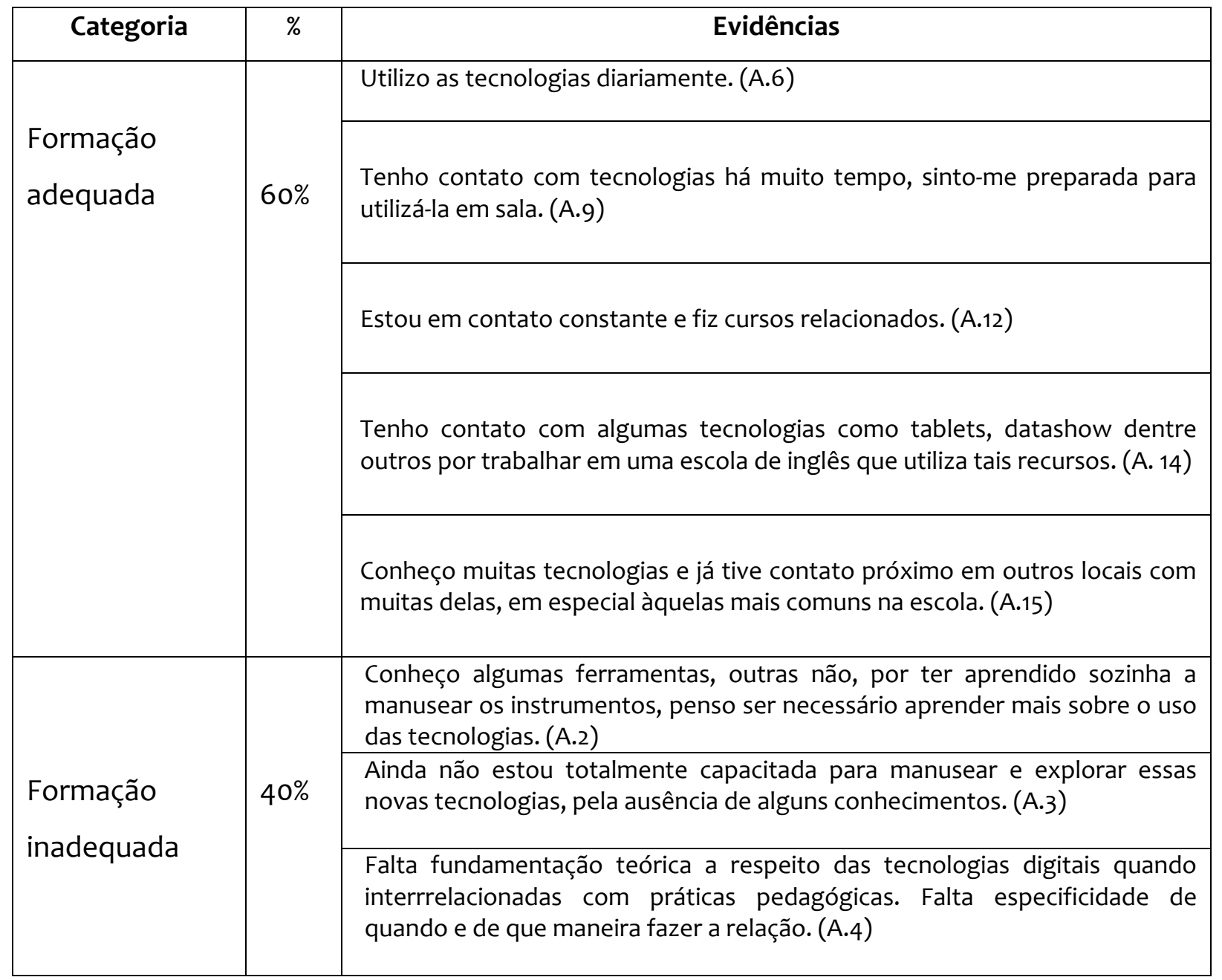

Fonte: Os autores

Os discentes que consideram ter uma formação adequada limitam-na ao contato e à familiaridade com a ferramenta como se sua habilidade instrumental fosse garantia de sucesso e não a reflexão e compreensão crítica destes dispositivos no contexto educacional. Nestes depoimentos, percebemos a presença de uma fragilidade na 
formação para o uso de tais ferramentas em uma perspectiva pedagógica que possa resultar em experiências significativas e inovadoras para ensinar e para aprender.

Os discentes que indicam formação inadequada evidenciam uma reflexão para além do saber manusear tais ferramentas que precisa ser ampliada, discutida e aperfeiçoada. Eles expressam que, apesar de conhecerem e manusearem algumas ferramentas, isso não é suficiente para que possam utilizar as tecnologias digitais para ensinar e aprender.

Tal realidade revela que somente conhecendo o papel que as tecnologias digitais “[...] desempenham no próprio processo de ensino e aprendizado dos professores permitirá aproveitar ao máximo seus benefícios, minimizando as possíveis dificuldades existentes, de maneira que se melhorem tanto a docência como o aprendizado" (BERNABÉ, 2012, p. 81).

A pesquisa evidenciou ainda que o curso não oferece espaços para discutir e abordar a temática no seu currículo e limita a tarefa somente a uma única disciplina de 62 horas no primeiro ano do curso. Uma análise primária dos dados obtidos parece revelar que esta, sozinha, não garante a formação técnica e pedagógica de que o discente necessita, uma vez que são muitos os aspectos a serem discutidos e vivenciados, como demonstrado no quadro 3:

Quadro 3: Experiências com o uso das tecnologias digitais no Curso de Pedagogia

\begin{tabular}{|c|c|}
\hline Categoria & Evidências \\
\hline \multirow{6}{*}{$\begin{array}{l}\text { Experiências } \\
\text { com o uso das } \\
\text { tecnologias }\end{array}$} & $\begin{array}{l}\text { Só teve uma disciplina no primeiro ano que, se não me engano, era semestral, sem } \\
\text { condições de aprender o manuseio de todas as tecnologias. (A.2) }\end{array}$ \\
\hline & $\begin{array}{l}\text { A única disciplina que buscou aprofundar sobre o assunto foi Educação e } \\
\text { Tecnologia. Na disciplina, houve discussões de alguns textos a respeito das } \\
\text { tecnologias em sala de aula. (A.4) }\end{array}$ \\
\hline & $\begin{array}{l}\text { A disciplina de pesquisa poderia contribuir, porém não ocorreu. A disciplina de } \\
\text { educação e tecnologia é a que mais se aproxima. (A.8) }\end{array}$ \\
\hline & Apenas uma disciplina que se aproximou da área de tecnologias. (A.9) \\
\hline & $\begin{array}{l}\text { Educação e Tecnologia, formação extremamente básica sobre como montar um } \\
\text { vídeo pelo computador. (A.10) }\end{array}$ \\
\hline & Só uma, mas penso que poderíamos ter tido mais aulas voltadas a isso. (A.11) \\
\hline no & $\begin{array}{l}\text { Educação e Tecnologia, mesmo assim não achei o suficiente, pois para utilizar os } \\
\text { recursos que foram apresentados, já era necessário ter um conhecimento básico. }\end{array}$ \\
\hline
\end{tabular}




\begin{tabular}{|l|l|}
\hline Curso de & (A.12) \\
\cline { 2 - 3 } Pedagogia & A disciplina de Educação e Tecnologia e também as disciplinas de Didática. (A.15) \\
\hline
\end{tabular}

Fonte: Os autores

Pelos depoimentos apresentados, vimos que, nas práticas do curso, não há espaço para vivenviar experiências com o uso dos dispositivos tecnológicos. Uma formação inicial deficiente em relação ao uso pedagógico das tecnologias digitais parece permear este cenário. A respeito desta questão, as Diretrizes Curriculares alertam para a

[...] necessidade de que o futuro professor experiencie, como aluno, durante todo o processo de formação, as atitudes, modelos didáticos, capacidades e modos de organização que se pretende venham a ser concretizados nas suas práticas pedagógicas. Nesta perspectiva, destacase a importância do projeto pedagógico do curso de formação na criação do ambiente indispensável para que o futuro professor aprenda as práticas de construção coletiva da proposta pedagógica da escola onde virá a atuar. (BRASIL, 2001, p. 30-31)

Em relação às experiências vivenciadas, os alunos manifestam que estas se deram basicamente pelo uso de duas ferramentas: power point, para a elaboração e apresentação de seminário, e movie maker, para a produção e edição de vídeo. É possível afirmar que o arcabouço do futuro docente, no que tange a experiências e reflexões relacionadas ao uso pedagógico das novas tecnologias, torna-se limitado e empobrecido, ficando evidente a fragilidade do curso em relação à formação adequada do futuro professor para lidar com as tecnologias digitais em sua prática pedagógica.

Tais depoimentos apontam para uma realidade que não é privilégio da IES pesquisada, mas uma situação que se repete em vários contextos, já que

[...] ainda são raras as iniciativas no sentido de garantir que o futuro professor aprenda a usar, no exercício da docência, computador, rádio, videocassete, gravador, calculadora, internet e a lidar com programas e softwares educativos. Mais raras, ainda, são as possibilidades de desenvolver, no cotidiano do curso, os conteúdos curriculares das diferentes áreas e disciplinas, por meio das diferentes tecnologias. (BRASIL, 2001, p. 24) 
Esta é uma situação preocupante, a formação dos educadores no que se refere às tecnologias digitais deve levar em consideração não apenas a instrumentalização do programa para determinado fim, mas para outros aspectos importantes, como:

[...] o uso dessas tecnologias enquanto ferramentas na formação inicial do professor, um instrumento nas disciplinas que fazem essa formação, e a formação dos alunos das licenciaturas para que possam lidar com tais tecnologias quando no exercício futuro de sua atividade profissional. (MARINHO, 2008, p. 58)

No que concerne a como deve ser esta formação e a estrutura do curso, bem como a maneira de se abordar e utilizar as tecnologias digitais para alcançar os propósitos sugeridos por Marinho (2008), os depoimentos dos alunos destacam os seguintes aspectos: uso de várias ferramentas tecnológicas nas diferentes disciplinas e a possibilidade de vivenciar experiências com as tecnologias digitais em sala de aula que os ajudem a entendê-las. Mas, para que se alcance este ideal, mesmo que parcialmente, é preciso formação adequada dos docentes formadores; é preciso que eles entendam os aspectos mais amplos que envolvem as tecnologias e o uso destas enquanto ferramentas de ensino e aprendizagem; é preciso que se estabeleça entre as novas tecnologias e as outras disciplinas da grade curriculiar "uma relação concreta" (A.6) e amadurecida por reflexões acadêmicas comprometidas com a realidade que o futuro professor vai experimentar: a realidade de inovações tecnológicas surpreendentes e desafiadoras; é preciso viabilizar uma realidade de uso ainda mais intenso de novas tecnologias na vida dos indivíduos, já que a realidade social pressiona para o consumo de novas tecnologias e as escolas precisam preparar cidadãos para o uso consciente e adequado delas e dos conhecimentos contruídos, que não serão completamente descartados por novas invenções.

Neste processo, o papel do docente formador é de grande relevância, porque ele vai direcionar caminhos, discutir possibilidades e propor reflexões e experiências. $\mathrm{Na}$ ótica dos discentes, os professores formadores têm conhecimento limitado sobre o uso pedagógico das ferramentas tecnológicas e isso parece contribuir para uma formação insuficiente, como declaram os alunos: 
O educador deve conhecer programas, blogs, sites, canais de vídeos entre outros que possam mostrar ao aluno, de uma forma diferenciada, como algumas coisas ocorrem. (A. 9)

Na Universidade, não há tantos recursos digitais e os que temos não são tão atuais ou os professores não estão aptos a utilizá-los. Creio que poderíamos começar por aí, inovando e ensinando, primeiramente aos docentes a melhor forma de utilizar e aproveitar-se destes (A.10)

O uso deve ser feito com sabedoria, isto é, o profissional, educador, precisa ser criativo e explorar ao máximo tudo que determinado recurso tecnológico tem a oferecer. (A.15)

O que foi aqui manifestado pelos discentes já está declarado nas Diretrizes Curriculares para Formação do Professor para a Educação Básica (BRASIL, 2001) e o fato de, conforme o que constatamos e o que estabelece o documento, serem muito raras as possibilidades de desenvolver, no cotidiano do curso, os conteúdos curriculares das diferentes áreas e disciplinas, por meio das diferentes tecnologias (BRASIL, 2001, p. 24), torna-se um agravante quando se pensa em utilizar tais dispositivos com propósitos pedagógicos que ultrapassem o uso como recurso de comunicação.

Tais afirmativas revelam prejuízos que esses discentes podem levar para sua atuação. Se o propósito é a superação de práticas reprodutivistas e cristalizadas em relação ao uso pedagógico das tecnologias digitais, é imprescindível que os discentes de um Curso de Pedagogia saiam da universidade com um panorama diferente daquele que dispunham quando nela entraram e é fundamental que, com a ampliação de seu repertório, possam inovar e melhorar suas práticas docentes, bem como sintam necessidade de, com frequência, rever suas práticas.

Estes pontos, certamente, devem ser tomados como pauta de discussão para que se possam trilhar caminhos na organização de uma formação que possibilite ao futuro docente entender e utilizar as tecnologias digitais a fim de que elas façam parte do "[...] planejar, regular e orientar as atividades próprias e alheias, introduzindo modificações importantes nos processos intra e interpsicológicos envolvidos no ensino e na aprendizagem" (COLL; MONEREO, 2010, p. 76). 


\section{Considerações Finais}

Esta é uma pesquisa de caráter exploratório explicativo e, para tanto, teve como propósito um estudo preliminar sobre as percepções que os discentes de um Curso de Pedagogia de uma instituição pública têm sobre a formação inicial para o uso das tecnologias digitais em suas futuras ações docentes. O desenvolvimento deste estudo possibilitou verificar que os discentes consideram as tecnologias digitais como relevantes no processo de ensino e aprendizagem, no entanto, a relação que estabelecem com elas não é avaliada consensualmente. Muitos, por não conhecerem bem conceitos teóricos e técnicos, consideram as tecnologias mais recentes como ameaças e não como possibilidades.

Foi possível constatar grande fragilidade em relação à formação adequada dos discentes para o uso das tecnologias digitais no contexto educativo, fato que os levou a não se sentirem preparados para usá-las em uma perspectiva pedagógica que possa resultar em experiências significativas e inovadoras, nem para ensinar, nem para aprender.

A pesquisa evidenciou, ainda, que o curso não oferece espaços e momentos para discutir e abordar a temática no seu currículo e limita a tarefa somente a uma única disciplina de 62 horas no primeiro ano do curso. Esta, por sua vez, não é suficiente para garantir a formação que o pedagogo necessita.

Outro aspecto relevante que a pesquisa traz à tona é a parca formação dos docentes formadores em relação ao uso e ao significado das tecnologias digitais na sua ação pedagógica. Este fato não favorece diferentes experiências que possam ajudá-los a ampliar seu arcabouço de conhecimentos sobre a temática.

Os aspectos achados nesta pesquisa levam à elaboração de novos questionamentos: Como deve ser reorganizado o Curso de Pedagogia e o que deve ser modificado nele para que as tecnologias digitais sejam contempladas nos aspectos pedagógico e prático? Como devem ser planejadas as ações docentes para que futuros professores vivenciem experiências que os ajudem a entender os limites e as possibilidades do uso das tecnologias digitais na educação? Que experiências precisam 
ser vivenciadas pelos discentes para que possam avançar em relação ao entendimento das tecnologias para além do aspecto instrumental?

É imprescindível, portanto, que os panoramas dos alunos sejam enriquecidos na universidade, tanto o panorama do conhecimento específico como o panorama do conhecimento pedagógico. É no tempo e no espaço da formação na licenciatura que o aluno deve ter a oportunidade de reconstruir ou construir novos saberes e experiências com base no aprofundamento do conhecimento específico, relacionando-o com o pedagógico e articulando as suas bases conceituais ao uso das tecnologias, que podem se bem usadas - ser excelentes catalizadoras do conhecimento significativo. 


\section{Referências}

ALAVA, Séraphin. (Org.). Ciberespaço e formações abertas: rumo a novas práticas educacionais? Porto Alegre: Artmed, 2002.

ANDRÉ, Marli Elisa Dalmazo Afonso. Etnografia da prática escolar. 11. ed. Campinas, SP: Papirus, 2004.

BARRETO, Raquel Goulart. Formação de professores, tecnologias e linguagens: mapeando velhos e novos (des)encontros. São Paulo: Loyola, 2002.

BARRETO, Raquel Goulart.Tecnologia e educação: trabalho e formação docente. Revista Educação e Sociedade. Campinas, SP, v. 25, n. 89, p. 1181-1201, set./dez. 2004. Disponível em: <http://www.cedes.unicamp.br>. Acesso em: 10 nov. 2012.

BERNABÉ, Iolanda. Os professores como aprendizes com as TICs. In: BARBA, Carme et al. Computadores em sala de aula: métodos e usos. Porto Alegre: Penso, 2012. p. 77-83.

BRASIL. Ministério da Educação. Secretaria de Educação Superior. Proposta de diretrizes curriculares para a formação inicial de professores da educação básica, em cursos de nível superior. Brasília, DF: MEC/SESu. 2001. Disponível em:

<http://portal.mec.gov.br/cne/arquivos/pdf/009.pdf>. Acesso em: 25 mar. 2013.

BRASIL. Conselho Nacional de Educação. Parecer CNE/CP n 3/2006, de 11 de abril de 2006: diretrizes curriculares nacionais para o curso de pedagogia. Brasília, DF. 2006. Disponível em: <http://portal.mec.gov.br/cne/arquivos/pdf/rcp01_06.pdf>. Acesso em: 18 mar. 2013.

COLL, César; MAURI, Teresa; ONRUBIA, Javier. A incorporação das tecnologias de informação e da comunicação na educação: do projeto técnico-pedagópgico às práticas de uso. In: COLL, César; MONEREO, Carles (Orgs.). Psicologia da educação virtual: aprender e ensinar com as tecnologias da informação e da comunicação. Porto Alegre: Artmed, 2010. p. 66-93.

COLL, César; MONEREO, Carles (Org.). Psicologia da educação virtual: aprender e ensinar com as tecnologias da informação e da comunicação. Porto Alegre: Artmed, 2010.

DEBORD, Guy. A sociedade do espetáculo. EbookBrasil, 2003. Disponível em: <http://www.ebooksbrasil.org/adobeebook/socespetaculo.pdf>. Acesso em: 15 maio 2013.

FREIRE, Paulo. Pedagogia do oprimido. 2. ed. Rio de Janeiro: Paz e Terra, 1975.

FREIRE, Paulo. Ação cultural para a liberdade e outros escritos. Rio de Janeiro: Paz e Terra, 1976.

FREITAS, Maria Teresa de Assunção de. Janela sobre a utopia: computador e internet a partir do olhar da abordagem histórico-cultural. In: REUNIÃO ANUAL DA ASSOCIAÇÃO NACIONAL DE PÓS-GRADUAÇÃO E PESQUISA EM EDUCAÇÃO, 32, 2009, Caxambu. Anais 
eletrônicos... Caxambu: ANPEd, 2009, p. 1-14. Disponível em:<http://www.anped.org.br/reunioes/32ra/arquivos/trabalhos/GT16-5857--Int.pdf>. Acesso em: 18 dez. 2012.

GATTI, Bernardete Angelina; BARRETO, Elba Siqueira de Sá (Coords.). Professores do Brasil: impasses e desafios. Brasília, DF: UNESCO, 2009. Disponível em: <http://unesdoc.unesco.org/images/0018/001846/184682por.pdf>. Acesso em: 20 dez. 2012.

GIL, Antonio Carlos. Como elaborar projetos de pesquisa. São Paulo: Atlas, 2002.

MARINHO, Simão Pedro. As tecnologias na formação inicial dos professores da educação básica: $O$ que pensam os alunos de licenciatura. Belo Horizonte: PUC, 2008. Disponível em:

<http://www.pucminas.br/imagedb/mestrado_doutorado/publicacoes/PUA_ARQ_ARQUI2 0120828101647.pdf >. Acesso em: 17 mar. 2013.

MARINHO, Simão Pedro ; LOBATO, Wolney. Tecnologias digitais na educação: desafios para a pesquisa na pós-graduação em educação. In: COLÓQUIO DE PESQUISA EM EDUCAÇÃO, 6. 2008, Belo Horizonte. Anais... 2008. v. 1. p. 1-9. Disponível em: <http://www.ich.pucminas.br/pged/arquivos/lp1/tecnologiadigitaiseducacao.pdf >. Acesso em: 20 ago. 2012.

PONTE, João Pedro da. Tecnologias de informação e comunicação na formação de professores: que desafios? Revista Iberoamericana de Educación, Espanha, n. 24, p. 6390, 21 set. 2000. Trimestral. Disponível em: <http://www.rieoei.org/rie24a03.PDF>. Acesso em: 15 set. 2013.

PRETTO, Nelson de Luca. Redes colaborativas, ética hacker e educação. Educação em Revista, Belo Horizonte, v. 26, n. 3, p. 305-316, dez, 2010. Disponível em: <http://www.scielo.br/pdf/edur/v26n3/v26n3a15.pdf>. Acesso em: 10 abr. 2013.

PRIMO, Alex. O aspecto relacional das interações na Web 2.o. E-Compós, Brasília, DF, v. 9, p. 1-21, 2007.

ROMANI, Cristóbal Cobo; KUKLINKI, Hugo Pardo. Planeta Web 2.0 inteligencia colectiva o medios fast food. Grup de Recerca d'Interaccions Digitals, Universitat de Vic. Flacso México. Barcelona / México DF. 2007. p. 101-134. Disponível em: <http://www.planetaweb2.net/>. Acesso em: 16 jan. 2013.

SACRISTÁN, Gimeno. Tendências investigativas na formação dos professores. In: PIMENTA, Selma Garrido; GHEDIN, Evandro (Orgs.). Professor reflexivo no Brasil: gênese e crítica de um conceito. 2. ed. São Paulo: Cortez, 2002. p. 82-98.

SANCHO, Juana. Maria; HERNANDEZ, Ferndando. et al. (Orgs.). Tecnologias para transformar a educação. Porto Alegre: Artmed, 2006. 
SILVA, Bento Duarte da. A inserção das tecnologias de informação e comunicação no currículo - repercussões e exigências na profissionalidade docente. In: MOREIRA, Antonio Flavio Barbosa; MACEDO, Elizabeth Fernandes de (Orgs.) Currículo, práticas pedagógicas e identidades. Porto: Porto Editora, 2002. p. 65-91.

SILVA, Marcos Sala de aula interativa: educação, comunicação, mídia clássica... 6. ed. São Paulo: Loyola, 2012.

VALENTE, José Armando. Análise dos diferentes tipos de softwares usados na educação. In: VALENTE, José Armando (Org.). O computador na sociedade do conhecimento. Campinas, SP: UNICAMP/NIED, 1999. p. 89-110.

VALENTE, José Armando. A espiral da aprendizagem e as tecnologias de informação e comunicação: repensando conceitos. In: JOLY, Maria Cristina Rodrigues Azevedo (Org.). A tecnologia no ensino: implicações para a aprendizagem. São Paulo: Casa do Psicólogo, 2002. p. 15-37. 